\title{
Probiotics in Prevention of Dental Caries - A Literature Review
}

\author{
Swarna.S.K ${ }^{1}$ and Nivedhitha.M.S 2 \\ ${ }^{1}$ Saveetha Dental College and Hospitals, Saveetha Institute of Medical and \\ Technical Sciences, Saveetha University, Chennai 600077 Tamil Nadu, India \\ ${ }^{2}$ Professor and Head of Department Department of Conservative Dentistry and \\ Endodontics Saveetha Dental College and Hospitals, Saveetha Institute of Medical and \\ Technical Sciences, Saveetha University Chennai 600077 Tamil Nadu, India
}

\section{ABSTRACT}

Dental caries is a microbial disease induced by oral biofilm containing Streptococcus mutans, leading to destruction of tooth structure. With better understanding of the Ecology and microbiology of the oral cavity and with the advent of Minimal Invasive Dentistry, there has been a shift in the treatment modalities of caries. Recently probiotics have been used extensively to promote a healthy oral flora. This review article aims to promote a better understanding of the probiotic strains, their mechanism of action and the various modes of delivery available. An electronic search was also performed using databases such as Google scholar, PubMed, Science direct and Scopus. Comparisons of different searches were carried out to delete the repeated studies. The articles published in any language other than English were excluded. Several studies proved that Probiotics can influence the caries balance locally through a direct contact with oral tissues and systemically through the gastrointestinal tract. Most of the probiotic strains currently available have been proved safe and promote both general and oral health. There are limited clinical trials with widely different study designs and target population. Also there is lack of evidence, regarding sustainability of the effect of Probiotics.

KEY WORDS: BIFIDOBACTERIA, CARIOGENIC BACTERIA, DENTAL CARIES, LACTOBACILLUS, PROBIOTICS, REPLACEMENT THERAPY, STREPTOCOCCUS MUTANS.

\section{INTRODUCTION}

The oral cavity is a very intricately balanced homeostatic chamber. Opportunistic bacteria take over, when the immune system is suppressed. Although usage of fluorides, chemoprophylactic agents and other preventive measures has led to a dramatic decline in dental caries, the ability to control the actual infection has been limited. The

\section{ARTICLE INFORMATION}

*Corresponding Author: nivedhitha@saveetha.com Received 22nd July 2020 Accepted after revision 26th Sep 2020 Print ISSN: 0974-6455 Online ISSN: 2321-4007 CODEN: BBRCBA

Thomson Reuters ISI Web of Science Clarivate Analytics USA and Crossref Indexed Journal

\section{Clarivate
Analytics}

NAAS Journal Score 2020 (4.31) SJIF: 2020 (7.728)

A Society of Science and Nature Publication,

Bhopal India 2020. All rights reserved.

Online Contents Available at: http//www.bbrc.in/

Doi: $h t t p: / / d x$.doi.org/10.21786/bbrc/13.8/190 concept of microbial ecological change as a mechanism of preventing dental disease is an important era in dentistry. Replacement therapy in adjunct with early colonisation of effective probiotics in the oral cavity helps in establishing a healthy oral microbiome(Teughels et al., 2008). The Food and Agriculture Organisation and World Health Organisation defined Probiotics in 2001, as "Live microorganisms which when administered in adequate amounts confer health benefits on the host"(Meurman and Stamatova, 2007).

We have numerous highly cited publications on well designed clinical trials and lab studies (Govindaraju, Neelakantan and Gutmann, 2017; Azeem and Sureshbabu, 2018; Jenarthanan and Subbarao, 2018; Manohar and Sharma, 2018; Nandakumar and Nasim, 2018; Teja, Ramesh and Priya, 2018; Janani and Sandhya, 2019; 
Khandelwal and Palanivelu, 2019; Malli Sureshbabu et al., 2019; Poorni, Srinivasan and Nivedhitha, 2019; Rajakeerthi and Ms, 2019; Rajendran et al., 2019; Ramarao and Sathyanarayanan, 2019; Siddique and Nivedhitha, 2019; Siddique et al., 2019; Siddique, Nivedhitha and Jacob, 2019). This has provided the right platforms for us to pursue the current study.

This review on the Effect of Probiotics in the prevention of dental caries was done to have a better understanding of the novel probiotic strains and their specific mechanism of action in colonisation of oral cavity and inhibiting the adherence and metabolism of cariogenic microflora. The main caries initiator streptococcus mutans has been studied extensively and various genetic modifications have been incorporated to alter its pathogenicity. The various studies done using different probiotic strains and the vehicles of probiotic delivery have been compiled to facilitate understanding of advancements in probiotic usage. Various studies were done to check for the efficacy of early colonisation of Probiotic bacteria in improving the general immune system of the individual. With advent of PCR and other molecular diagnostic methods, newer Probiotic strains with better safety and efficacy have been characterised and used.

\section{MATERIAL AND METHODS}

An electronic search was also performed using databases such as Google scholar, PubMed, Science direct and Scopus using keywords such as probiotics, probiotic bacteria, dental caries, cariogenic bacteria, Streptococcus mutans, Lactobacillus which were used as isolated or in combinations using different Boolean operators. Comparisons of different searches were carried out to delete the repeated studies. Then abstracts of all available articles were examined. All studies, which studied probiotic strains with relevance to oral health were included in the study. The articles published in any language other than English were excluded.

History: The term PROBIOTIC, meaning "for life", is derived from a Greek language. The concept of Probiotics was 1st proposed by Nobel Laureate Elie Metchnikoff in 1908(Mercenier, Pavan and Pot, 2003; Tannock, 2003). Ferdinand Virgin first introduced the term "probiotic" differentiating it from antibiotics. In 1965, Lilly and Stillwell mentioned that probiotics contain bacteria that are capable of producing substances that stimulate the growth of other bacteria. Man and Spoering in 1974, discovered that fermented yoghurt reduced serum cholesterol. In 1984, Holocombh et al identified Bifidobacterium. WHO IN 1994 described Probiotics as the next most important step in the immune defense mechanism following antibiotic resistance.

Criteria For Probiotic Bacteria: Any microorganism that is found to be beneficial to the host can be considered as a probiotic only if the genus and species can be identified and characterized according to Internationally accepted methods. The organism has to succeed in various in vitro, animal and clinical trials to check for its pathogenicity.

The FAO and WHO have recommended that probiotics strains can be characterized by their

- Spectrum of antibiotic resistance

- Metabolic and hemolytic activities

- Ability of toxin production

- Pathogenicity in immunosuppressed animal models

- The resistance pattern of probiotic strains should be studied to avoid transfer of antibiotic resistance genes through lateral gene transfer (Duncan, 2003)

- $\quad$ Should be able to create a favourable environment by modulating ph and enhancing action on the oxidation reduction potential, thus preventing establishment of pathogenic bacteria.

Characteristics of Novel Probiotic Strains

- Should be non-toxic and non- pathogenic

- Should be microbiologically characterized

- Contain a large number of viable cells

- Remain viable during storage and use

- $\quad$ Should have been subjected to Randomised Control Trial

- Should be stable in acidic and alkaline environment

Benefits of Probiotics in General Health: Bacterial colonisation begins right from the birth of the infant. The adequate establishment of the intestinal flora after birth plays a crucial role in the development of the Innate and Adaptive immune system. The newborn infant's gestational age, mode of delivery and diet influences this initial colonisation. Neonates who are born by caesarian delivery, preterm, exposed to prenatal and perinatal antibiotics show a delay in intestinal commensal probiotic bacterial colonisation. Breast fed infants are found to have Bifidobacteria predominant colonisation , whereas formula fed infants have equal colonization with Bacteroides and Bifidobacteria species(Yoshioka, Iseki and Fujita, 1983; Penders et al., 2006). The infants are exposed to the bacterial components from their mother during feeding. They might acquire few commensals during the early days of life. This process is termed as “Bacterial imprinting”(Perez et al., 2007).

Some of the Probiotic effects on General health are as follows:

- Probiotics play a major role in balancing gut flora

- Increased resistance to infectious diseases (Perdigon et al., 1995; Fuller, 1997) (Perdigon et al., 1995; Fuller, 1997; Arunachalam, Gill and Chandra, 2000)

- Alleviates Lactose intolerance (McDonough et al., 1987)

- Lowers the serum cholesterol by bile salt deconjugation (Fuller, 1997)

- Reduction in allergy and respiratory infections (Hatakka et al., 2001) 
- Balances the immune response of the individual resulting in control of Inflammatory Bowel Syndrome

- Prevention of antibiotic associated diarrhea, gastritis ,vaginal and urogenital infections.

- It lowers the mutagenic and toxigenic reactions in the gut which predisposes to colon cancer.

- Alleviates food allergy symptoms in infants by immunomodulation

- Produces vitamins and other nutritional factors.

The predominantly used Probiotics mainly belong to two genera, Lactobacillus and Bifidobacterium species. There are more than 100 species of Lactobacillus that have been identified like Lactobacillus acidophilus, Lactobacillus brevis, Lactobacillus casei, Lactobacillus rhamnosus and Lactobacillus salivarius. They are capable of producing digestive enzymes capable of metabolizing proteins and carbohydrates. Lactobacillus species help in synthesis of vitamin $B$, vitamin $K$, and also helps in the breakdown of bile salts. Next to Lactobacilli, Bifidobacteria are probiotics commonly used for improving microflora of newborn and breastfed children. However the levels of Bifidobacteria decrease gradually after weaning and are replaced by potentially pathogenic bacteria.

Role of Probiotics in Oral Health: The oral cavity houses a great diversity of microbial species and each surface of the oral cavity is covered by numerous bacterial communication systems. Keigser et al., reported the presence of more than 1000 species of bacteria which may be in planktonic state or integrated into biofilms. (Keijser et al., 2008) The most common probiotic strains in the oral cavity include Lactobacillus and Bifidobacterium.

The probiotics helps in reducing the pathogenic oral microflora and has the following effects in the oral cavity:

- Helps in prevention of Dental caries.

- Promotes periodontal health.

- Prevention of candidiasis.

- Reduction of Halitosis(Stecksén-Blicks, Sjöström and Twetman, 2009)

Mechanism of Action of Probiotic Bacteria in Prevention of Dental Caries: Dental caries are multifactorial in origin and the most commonly involved organisms are Streptococcus mutans as the initiator and Lactobacilli as secondary invaders which results in caries progression. The process of tooth decay ensues by the progression of adhesion, co-aggregation and secondary colonisation. The biofilms are important mediators that encourage adhesion. In-vitro studies have assessed adhesion by measuring the attachment of bacteria to saliva coated hydroxyapatite (HA) and oral epithelium (Stamatova et al., 2009). Among Probiotic strains Lactobacillus rhamnosus GG exhibited highest values of adhesion, comparable to those of the early tooth coloniser Streptococcus sanguis(Gilliland and Kim, 1984).
S.mutans is the most common organism that leads to the development of caries(Nikawa et al., 2004; Beighton, 2005). S.mutans is an acidogenic bacteria and it rapidly metabolizes carbohydrates resulting in lowering of $\mathrm{pH}$ in the oral cavity that leads to disturbance in hemostasis in the oral microbial community(Hedberg et al., 2008).

- Probiotic bacteria inhibits biofilm formation by competing with pathogenic bacteria for adhesion sites, nutrients and growth factors.

- Interfere in metabolism of substrates by pathogenic bacteria.

- They are capable of producing antimicrobial substances such as organic acids, hydrogen peroxide, mutacin, bacitracin, Lactase, bacteriocin, biosurfactants and fatty acids for antagonizing the pathogens.(Meurman, 2009)

- The antimicrobial substances produced by the Probiotics are more effective in acidic than in alkaline medium. Lactobacillus salivarius produces a bacteriocin called salivacin 140, Lactobacillus plantarum produces plantaricin 423, Lactobacillus reuteri produces reuterin and reutesilin and Lactobacillus acidophilus produces acidocin J1229.

- To have a beneficial effect in the oral cavity, probiotics should form a biofilm that acts as a protective lining for oral tissues against oral diseases.

- Probiotics affects the structural integrity of the pellicle layer. They lower the levels of salivary agglutinin which is essential for the adhesion of Streptococcus mutans to the tooth surface.

- Probiotics also lower the peroxidase levels thus improving the antibacterial activity of saliva. They lead to changes in oral $\mathrm{pH}$ and redox potential.

- $\quad$ Selection pressure on developing microflora towards colonization by less pathogenic species.

- Prevent plaque formation by neutralizing free electrons.

- Stimulate non specific immunity and modulate humoral and cellular immune response

- Enhances host immune response by production of IgA and defensins.

- Decreases production of matrix metalloproteinases.

- Leading to inactivation of probiotic bacteria by mechanisms of Aggregation and coaggregation.

Probiotics should be installed in the oral cavity for a specified period of time in order to exhibit its actions. They should adhere to the dental tissues for them to establish a cariostatic effect and thus should be part of biofilm to fight against the cariogenic bacteria(Hatakka et al., 2001; Grudianov, Dmitrieva and Fomenko, 2002). The development of levels of secretory immunoglobulins in saliva of newborns was studied under physiological conditions and after artificial colonisation with nonpathogenic, probiotic bacterial strain of Escherichia coli. The early colonization of E.coli would activate the immune system to produce specific antibodies and immunoglobulins(Vancíková et al., 2003). Thus it 
was proved by various studies that early colonisation of infants with Probiotic bacteria had a significant improvement in the overall immune system. Lactobacilli are known to play an important role in the maintenance of human health by simulating a native immunity and protection against infection of the pathogenic bacteria (Gill and Prasad, 2008).

Table 1. Commonly used Anti-cariogenic Probiotic strains and their specific actions

\begin{tabular}{|c|c|}
\hline Probiotic strains & Mechanism of action \\
\hline Lactobacillus reuteri & $\begin{array}{l}\text { Co-aggregation(Jørgensen et al., 2017) } \\
\text { Secretion of } 2 \text { bacteriocins namely, } \\
\text { reuterin and reutericyclin. } \\
\text { Inhibits cytokine secretion that } \\
\text { initiates inflammation. } \\
\text { Reduces dental plaque and gingivitis. } \\
\text { (Stecksén-Blicks, Sjöström and Twetman, 2009; } \\
\text { Schlagenhauf et al., 2016) Reduces } \\
\text { pro-inflammatory cytokines in GCF. }\end{array}$ \\
\hline Lactobacillus salivarius WB21 & $\begin{array}{l}\text { Improves periodontal clinical } \\
\text { parameters in smokers (Shimauchi et al., 2008) }\end{array}$ \\
\hline $\begin{array}{l}\text { Lactobacillus species } \\
\text { (Gruner, Paris and Schwendicke, 2016) }\end{array}$ & $\begin{array}{l}\text { Reduces ability of candida albicans to } \\
\text { form biofilms on dentures } \\
\text { (Ujaoney et al., 2014) } \\
\text { Helps in synthesis of vitamin K and } \\
\text { also helps in breakdown of bile salts. } \\
\text { They help in enhancing innate and acquired } \\
\text { immunity as well as inhibition } \\
\text { of pro inflammatory mediators. } \\
\text { Lactobacillus and Bifidobacteria inhibit } \\
\text { the growth of streptococci and candida species. } \\
\text { Co-aggregate Streptococcus mutans. }\end{array}$ \\
\hline $\begin{array}{l}\text { Lactobacillus rhamnosus GG } \\
\text { (Schwendicke et al., 2014) } \\
\text { and Lactobacillus paracasei } \\
\text { (Chuang et al., 2011) }\end{array}$ & $\begin{array}{l}\text { Antagonizes S.mutans and } \\
\text { Porphyromonas gingivalis. }\end{array}$ \\
\hline $\begin{array}{l}\text { Lactobacillus rhamnosus } \\
\text { GG (ATCC 53103) }\end{array}$ & $\begin{array}{l}\text { Inhibitory effect on the growth of } \\
\text { Streptococcus sobrinus in an agar } \\
\text { overlay technique. }\end{array}$ \\
\hline Lactobacillus salivarius WB21 & $\begin{array}{l}\text { Significantly decreased plaque } \\
\text { index and probing and pocket depth. }\end{array}$ \\
\hline $\begin{array}{l}\text { Lactobacillus reuteri ATCC 5573, } \\
\text { Bifidobacterium DN - } 173010 \\
\text { by Caglar et al }\end{array}$ & $\begin{array}{c}\text { Significant reduction of } \\
\text { S.mutans(Caglar, Kargul } \\
\text { and Tanboga, 2005) }\end{array}$ \\
\hline S.mutans strain BCS3-L1 & $\begin{array}{l}\text { Produces an antimicrobial peptide } \\
\text { called mutacin } 1140 \text { against } \\
\text { pathogenic S.mutans(Chen and Wang, 2010) }\end{array}$ \\
\hline S.mutans with gtfC gene mutation & $\begin{array}{l}\text { Inhibits production of extracellular } \\
\text { glucan which is an important } \\
\text { extracellular matrix } \\
\text { component in oral biofilms. }\end{array}$ \\
\hline $\begin{array}{l}\text { S.salivarius M18 (strain Mia) by } \\
\text { Suzuki and Nicholas et al (Heng et al., 2011) }\end{array}$ & $\begin{array}{l}\text { Interaction with epithelium } \\
\text { (Manning et al., 2016) } \\
\text { Broad spectrum inhibitory activity } \\
\text { against streptococcal pathogens } \\
\text { (Kumada et al., 2009) }\end{array}$ \\
\hline
\end{tabular}


Subjects without caries are colonised by Lactobacilli, which possess a significantly increased capacity to suppress the growth of Streptococcus mutans compared to subjects with arrested or active caries(Simark-Mattsson et al., 2007). Lactobacillus rhamnosus GG and Lactobacillus reuteri have the unique property of reducing the cariogenic Streptococcus mutans counts, thus suggested widely for prophylaxis of caries. Lactobacillus species strain GG is an effective probiotic as it produces organic acids, hydrogen peroxide, bacteriocins and adhesion inhibitors against Streptococcus species (Silva et al., 1987). L.rhamnosus strains, L.paracasei F19 and L.reuteri do not ferment sucrose and are relatively safe probiotic strains in caries- prophylaxis.

Table 2. Commercially available products for local delivery of Probiotics.

\begin{tabular}{|l|c|c|}
\hline Name of the commercial product & Strains present & Probiotic actions \\
\hline $\begin{array}{l}\text { New Evora kids Oral } \\
\text { Probiotic Chew }\end{array}$ & $\begin{array}{c}\text { Streptococcus oralis } \\
\text { strain KJ3 } \\
\text { Streptococcus uberis } \\
\text { strain KJ2 } \\
\text { Streptococcus rattus } \\
\text { strain JH145 }\end{array}$ & $\begin{array}{c}\text { Maintenance of dental } \\
\text { and gingival health } \\
\text { between professional visits }\end{array}$ \\
\hline $\begin{array}{l}\text { Plidenta Pro-t-action } \\
\text { toothpaste }\end{array}$ & $\begin{array}{c}\text { Lactobacillus } \\
\text { paracasei }\end{array}$ & $\begin{array}{c}\text { Co-aggregation of } \\
\text { cariogenic S.mutans }\end{array}$ \\
\hline
\end{tabular}

Various Studies Done Using Probiotic Bacteria: Keller et al had shown that Lactobacilli displayed co-aggregation activity(Table 1) and inhibited growth of pathogenic strain of mutans streptococci(Keller et al., 2011). Meurman et al in 2005, demonstrated that consumption of milk on a regular basis containing Lactobacillus rhamnosus GG strain reduced initial carious lesions in kindergarten children. Nase et al and Cagler et al showed that administration of Lactobacillus reuteri ATCC 55739 OR Bifidobacterium DN 173010 induced significant reduction of S.mutans in saliva.(Table 1). Hillman et al introduced a non acid producing S.mutans strain that produces a bacteriocin active against other S.mutans strains into the oral cavity to replace the naturally occuring cariogenic strains. Hillman et al studied that $\mathrm{JH}$ 145, a variant of S.rattus was able to colonise tooth surfaces readily compared to S.mutans (Table 2). Thus S.rattus JH 145 had potential for use as probiotic in prevention of dental caries.(Hillman et al., 2009)

Petti et al reported that yoghurt containing S.thermophilus and L.bulgaricus had selective bactericidal effects on streptococci of mutans group. Nikawa et al in 2004, reported that consumption of yoghurt containing lactobacillus reuteri over a period of 2 weeks have shown in reduction of S.mutans in saliva upto 80\%(Nikawa et al., 2004). Cagler et al (2006) by a comparative study, demonstrated a reduced S.mutans level in patients receiving fluid or tablet probiotic forms(Caglar, Kargul and Tanboga, 2005). He also found a significant reduction in the streptococcus mutans count after the administration of xylitol enriched chewing gums. Hang et al reported that S. salivarius M18( formerly strain Mia) exhibited broad spectrum activity against several streptococcal pathogens, notably S.mutans.(Table 1)

Glavina et al., studies the effect of yoghurt containing Lactobacillus rhamnosus ATCC 53103-LGG on reducing the Streptococcus mutans and Lactobacillus species salivary counts in children. (Glavina et al., 2012). 12) Petersson et al found that the regular consumption of probiotic reverse primary root caries in older individuals(Petersson et al., 2011). Koll- Klais et al (2005) studied various strains of lactobacilli and found inhibitory action of 69\% strains on the growth of S.mutans and 82\% strains inhibited the growth of P.gingivalis(Kõll et al., 2008). Ahola et al., 2002 performed a study on adults by administering them cheese containing L.rhamnosus GG and L.rhamnosus LC 705 for 3 weeks and a significant reduction in the level of streptococcus mutans was noted.(Ahola et al., 2002). Hedayati -Hajikand et al., found that the combined use of chewable tablets with ProBiora3 (combination of S.uberis, S.oralis KJ3 and S.rattus JH145) and the daily use of fluoride toothpaste decreased early demineralization of the enamel, but had no effect on carious lesions.

Comelli et al, 2002 encouraged the selection of non-pathogenic dairy bacterial strains that were able to decrease the cariogenic potential of dental plaque. Specifically they found that Lactococcus lactis NCC2211 can be incorporated into a biofilm and is capable of modulating the growth of Streptococcus sobrinus OMZ176 (Comelli et al., 2002). Montalo et al., (2004) studied the probiotic strains of L.sporogenes, L.bifidum, L.bulgaricus, L.thermophilus, L.acidophilus and demonstrated increased counts of lactobacilli with significant decrease in levels of streptococcus mutans (Montalto et al., 2004). Hatakka et al., (2007) did a study and concluded that Lactobacillus rhamnosus GG and Propionibacterium JS reduced risk of high yeast counts and hyposalivation. The bacterium W.cibaria 110, which was isolated from fermented fish in Thailand, has been shown to produce the bacteriocin Weisselicin 110, which prevents colonisation of certain gram positive bacteria(Srionnual et al., 2007). 
Gruner et al, 2016 systematically reviewed the dental benefits of probiotics and concluded that the current evidence was not sufficient to recommend probiotics for managing dental caries, but suggested as supportive therapy for gingivitis or periodontitis(Gruner, Paris and Schwendicke, 2016). Montalto et al, 2004 did a randomised clinical trial and stated that the probiotic treatment could increase lactobacilli counts(Montalto et al., 2004). Amez et al suggested treatment with probiotics as bacteriotherapy that reduced the colony forming units of streptococcus mutans.(Seminario-Amez et al., 2017). $\mathrm{Hu}$ et al and Mundula et al, studied that the probiotics had a favourable effect in treating oral candidiasis( $\mathrm{Hu}$ et al., 2019)(Mundula et al., 2019).

Vehicles for Probiotic Supplements: Probiotics are generally isolated from healthy humans or they are derived from fermented food. The contact between plaque and the probiotic should be long enough for enhanced actions of probiotic bacteria. Thus ideal vehicles for the delivery of probiotics and time of contact of probiotics to oral surfaces is pivotal in achieving optimum probiotic effects. In food technology, dairy products containing probiotic lactobacilli in combination with prebiotics are currently developed, which may be useful as a symbiotic functional food(Corcoran et al., 2004). Evaluation of a suitable vehicle for probiotic administration is very essential for improving efficacy of probiotic action. Most naturally occuring Probiotics are found in fermented dairy products. Milk acts as a buffer to the acid produced. Milk itself contains calcium, calcium lactate and other organic and inorganic compounds that are anticariogenic and reduce the colonisation of cariogenic pathogens.

Probiotics are incorporated into food products and available in various forms as follows:

- Added to a beverage or food in the form of cultural concentration.

- Inoculated into prebiotic fibres

- Inoculated into milk or milk based products such as milk, yoghurt, kefir and cheese.

- Non- dairy products such as powder, capsule, gelatin tablets are packed with commercially prepared probiotics.

Nadelman et al, systematically reviewed the effect of dairy products containing probiotics and stated that it could support prevention of dental caries(Nadelman et al., 2018)Milk and cheese have been widely used as vehicles for probiotic delivery and they have added advantage of having casein phosphopeptide which has a major role in "biomineralization". Cheese was thought to have more local effect as it cleared more slowly from mouth than milk. Caglar et al administered L.reuteri ATCC 55730 in capsule and straw forms in young adults for 3 weeks and raised the possibility of a systemic effect along with a local effect (Table 1). Yli-Knutilla studied the colonisation of Lactobacillus rhamnosus GG in the oral cavity in a 14 day trial period and observed that there was less substantive effect in the oral cavity since it lasted only for one week(Table 1).
Safety Concerns in Probiotic Bacteria: Probiotic bacteria should be non-pathogenic, should not have any growth promoting effects on pathogenic bacteria, should not be able to transfer the antibiotic resistant genes and should be capable of maintaining a stable and healthy oral microflora. The safest probiotic species include Lactobacilli, bifidobacteria and lactococci. Bifıdobacteria are evaluated and are considered safe for use in baby formulas(Saavedra et al., 2004). Most commonly used Probiotics are acidogenic and have the capability to dissolve hard structures of the tooth namely, enamel and dentin. (Toi, Mogodiri and Cleaton-Jones, 2000). When lactobacilli are administered orally, they establish themselves in the oral cavity and their mechanism of action should not support formation of caries.

Many lactobacilli strains are resistant to vancomycin, which raises the concern regarding the possible transfer of such resistance to more pathogenic organisms, particularly enterococci and staphylococcus aureus. Probiotic organisms like Enterococcus, Bacillus and other spore forming bacteria are not regarded as safe probiotics due to increased risk of bacteremia and endocarditis development(Snydman, 2008).

Newer Approaches In Probiotic Usage: Interference with signaling mechanism: Several pathogenic properties of S.mutans are regulated by a quorum sensing mechanism involving Competence Stimulating peptide(CSP) as the signalling molecule. Addition of high concentration of CSP can induce death of S.mutans(Snydman, 2008; Chen and Wang, 2010).

Targeted antimicrobial therapy via a novel STAMP technology: Indiscriminate killing of all the microbes by conventional antimicrobials disrupts the ecological balance of indigenous microbiota. Eckert et al formulated a new class of antimicrobials called Specifically Targeted Antimicrobial Peptides (STAMP).

- Specific binding to selected pathogens facilitates the specific action of probiotics(He et al., 2009).

- $\quad$ The targeting moiety provides binding to a selected pathogen and facilitates the targeted delivery of an antimicrobial peptide.

- Recombinant DNA technology has been used to delete gene encoding lactate dehydrogenase in BCS3-L1(Table 1) making it unable to produce lactic acid. This effector strain secrete mutacin 1140 that inhibits all pathogenic strains of S.mutans (Chen and Wang, 2010)

\section{Future Trends In Probiotic Therapy}

- Probiotics can be used as passive local immunization against dental caries. Systemic immunization with a multivalent vaccine, L. rhamnosus GG was chosen as a vehicle to harbor IgG because of its wide range of health benefits in humans and animals.

- High titres of antibodies against human cariogenic bacteria, S. mutans and S. sobrinus, were produced in bovine colostrum by a vehicle of fermented milk (Wei et al., 2002) 
- Probiotic bacteria like E.coli if colonized early in new born may stimulate immune response to produce antibodies and immunoglobulins

- Advances in Biomedical engineering is necessary to develop systems that deliver bacteria to the host, which include encapsulation of probiotics to rehydrate at specific sites and encasing prebiotics in nano- aggregates thus providing protection in the gastric environment, ensuring delivery at a $\mathrm{pH}$ of 7.4

- Capsules coated with biosensors that can ascertain the favorable conditions for release of probiotics are on the horizon in molecular research.

- In food technology, dairy products containing natural Probiotics like Lactobacilli are combined with prebiotics to be used as symbiotic functional food(Corcoran et al., 2004)

- Studies are also being extensively made in the field of Oncology, regarding the use of Probiotics to counteract the serious systemic infections that occur in immunosuppressed patients undergoing long term chemotherapy.

\section{RESULTS AND DISCUSSION}

The various studies included clearly demonstrate that most probiotic strains commonly used are as safe as commensals. Thus, the Probiotics can influence the caries balance locally through a direct contact with oral tissues and systemically through the gastrointestinal tract. Recent advances in vehicles of probiotics have facilitated the use of probiotics among all common people. This review of literature would help the dentist, in understanding the properties and mechanism of action of probiotics better and help in initiating further systematic studies with controlled clinical trials in order to establish probiotics as preventive therapy for dental caries

\section{CONCLUSION}

The control of oral biofilm using Probiotics has been used as a preventive strategy to dental caries. Some of the beneficial Probiotic strains are found to indigenous part of healthy oral microbiota which encourages a lot of researchers to use Probiotics as a part of Bacteriotherapy in management of Dental caries. Probiotics can influence the oral cavity and the caries balance locally through a direct contact with oral tissues and systemically through the gastrointestinal tract.

Most of the probiotic strains currently available have been proved safe and promote both general and oral health. Early colonization of Probiotics in infants has gained a lot of popularity in developing a healthy oral microbiome. As the composition of biofilm in infants is immature, it has been suggested that an intake of probiotic bacteria, early in life could lead to permanent colonization, but still studies needed to support this assumption. Probiotics that are able to deliver new and novel therapeutics are emerging with site specificity and well defined efficacy and termed as "designer probiotics".
Limited clinical trials, widely different study designs and target population and lack of knowledge of sustainability of the effect of Probiotics are some of the drawbacks encountered in the usage of Probiotics in Dental therapeutics. Multi-disciplinary approach combining the fields of Dentistry, Biomedical Engineering along with Genetic technology is needed to identify the most safe and effective Probiotic strains and administer optimal administration regimes.

\section{ACKNOWLEDGEMENT}

Both the authors have equally contributed to the study.

Conflicts of Interest: There are no conflicts of interest

\section{REFERENCES}

Ahola, A. J. et al. (2002) 'Short-term consumption of probiotic-containing cheese and its effect on dental caries risk factors', Archives of oral biology, 47(11), pp. 799-804.

Arunachalam, K., Gill, H. S. and Chandra, R. K. (2000) 'Enhancement of natural immune function by dietary consumption of Bifidobacterium lactis (HN019)', European journal of clinical nutrition, 54(3), pp. 263-267.

Azeem, R. A. and Sureshbabu, N. M. (2018) 'Clinical performance of direct versus indirect composite restorations in posterior teeth: A systematic review', Journal of conservative dentistry: JCD, 21(1), pp. 2-9. Beighton, D. (2005) 'The complex oral microflora of high-risk individuals and groups and its role in the caries process', Community dentistry and oral epidemiology, 33(4), pp. 248-255.

Caglar, E., Kargul, B. and Tanboga, I. (2005) 'Bacteriotherapy and probiotics' role on oral health', Oral diseases, 11(3), pp. 131-137.

Chen, F. and Wang, D. (2010) 'Novel technologies for the prevention and treatment of dental caries: a patent survey', Expert opinion on therapeutic patents, 20(5), pp. 681-694.

Chuang, L.-C. et al. (2011) 'Probiotic Lactobacillus paracasei effect on cariogenic bacterial flora', Clinical oral investigations, 15(4), pp. 471-476.

Comelli, E. M. et al. (2002) 'Selection of dairy bacterial strains as probiotics for oral health', European journal of oral sciences, 110(3), pp. 218-224.

Corcoran, B. M. et al. (2004) 'Comparative survival of probiotic lactobacilli spray-dried in the presence of prebiotic substances', Journal of applied microbiology, 96(5), pp. 1024-1039.

Duncan, M. J. (2003) 'Genomics of oral bacteria', Critical reviews in oral biology and medicine: an official publication of the American Association of Oral 
Biologists, 14(3), pp. 175-187.

Fuller, R. (1997) 'Introduction', in Probiotics 2, pp. $1-9$.

Gill, H. and Prasad, J. (2008) 'Probiotics, immunomodulation, and health benefits', Advances in experimental medicine and biology, 606, pp. 423454.

Gilliland, S. E. and Kim, H. S. (1984) 'Effect of viable starter culture bacteria in yogurt on lactose utilization in humans', Journal of dairy science, 67(1), pp. 1-6. Glavina, D. et al. (2012) 'Effect of LGG yoghurt on Streptococcus mutans and Lactobacillus spp. salivary counts in children', Collegium antropologicum, 36(1), pp. 129-132.

Govindaraju, L., Neelakantan, P. and Gutmann, J. L. (2017) 'Effect of root canal irrigating solutions on the compressive strength of tricalcium silicate cements', Clinical oral investigations, 21(2), pp. 567-571.

Grudianov, A. I., Dmitrieva, N. A. and Fomenko, E. V. (2002) '[Use of probiotics Bifidumbacterin and Acilact in tablets in therapy of periodontal inflammations]', Stomatologiia, 81(1), pp. 39-43.

Gruner, D., Paris, S. and Schwendicke, F. (2016) 'Probiotics for managing caries and periodontitis: Systematic review and meta-analysis', Journal of dentistry, 48, pp. 16-25.

Hatakka, K. et al. (2001) 'Effect of long term consumption of probiotic milk on infections in children attending day care centres: double blind, randomised trial', BMJ , 322(7298), p. 1327.

Hedberg, M. et al. (2008) 'Sugar fermentation in probiotic bacteria - anin vitrostudy', Oral microbiology and immunology, 23(6), pp. 482-485.

Heng, N. C. K. et al. (2011) 'Genome sequence of the bacteriocin-producing oral probiotic Streptococcus salivarius strain M18', Journal of bacteriology, 193(22), pp. 6402-6403.

He, X. et al. (2009) 'Achieving probiotic effects via modulating oral microbial ecology', Advances in dental research, 21(1), pp. 53-56.

Hillman, J. D. et al. (2009) 'A spontaneous lactate dehydrogenase deficient mutant ofStreptococcus rattusfor use as a probiotic in the prevention of dental caries', Journal of applied microbiology, 107(5), pp. 1551-1558.

$\mathrm{Hu}$, L. et al. (2019) 'In vivo effectiveness and safety of probiotics on prophylaxis and treatment of oral candidiasis: a systematic review and meta-analysis', BMC oral health, 19(1), p. 140.

Janani, K. and Sandhya, R. (2019) 'A survey on skills for cone beam computed tomography interpretation among endodontists for endodontic treatment procedure', Indian journal of dental research: official publication of Indian Society for Dental Research, 30(6), pp. 834-838.

Jenarthanan, S. and Subbarao, C. (2018) 'Comparative evaluation of the efficacy of diclofenac sodium administered using different delivery routes in the management of endodontic pain: A randomized controlled clinical trial', Journal of conservative dentistry: JCD, 21(3), pp. 297-301.

Jørgensen, M. R. et al. (2017) 'Probiotic Lactobacillus reuteri has antifungal effects on oral Candida species in vitro', Journal of oral microbiology, 9(1), p. 1274582.

Keijser, B. J. F. et al. (2008) 'Pyrosequencing analysis of the oral microflora of healthy adults', Journal of dental research, 87(11), pp. 1016-1020.

Keller, M. K. et al. (2011) 'Co-aggregation and growth inhibition of probiotic lactobacilli and clinical isolates of mutans streptococci: Anin vitrostudy', Acta odontologica Scandinavica, 69(5), pp. 263-268.

Khandelwal, A. and Palanivelu, A. (2019) 'Correlation Between Dental Caries And Salivary Albumin In Adult Population In Chennai: An In Vivo Study', Brazilian Dental Science, 22(2), pp. 228-233.

Kõll, P. et al. (2008) 'Characterization of oral lactobacilli as potential probiotics for oral health', Oral microbiology and immunology, 23(2), pp. 139-147.

Kumada, M. et al. (2009) 'Inhibiting effects of Enterococcus faecium non-biofilm strain on Streptococcus mutans biofilm formation', Journal of microbiology, immunology, and infection = Wei mian yu gan ran za zhi, 42(3), pp. 188-196.

Malli Sureshbabu, N. et al. (2019) 'Concentrated Growth Factors as an Ingenious Biomaterial in Regeneration of Bony Defects after Periapical Surgery: A Report of Two Cases', Case reports in dentistry, 2019, p. 7046203.

Manning, J. et al. (2016) 'Investigation of Streptococcus salivarius-mediated inhibition of pneumococcal adherence to pharyngeal epithelial cells', BMC microbiology, 16(1), p. 225.

Manohar, M. P. and Sharma, S. (2018) 'A survey of the knowledge, attitude, and awareness about the principal choice of intracanal medicaments among the general dental practitioners and nonendodontic specialists', Indian journal of dental research: official publication of Indian Society for Dental Research, 29(6), pp. 716-720.

McDonough, F. E. et al. (1987) 'Modification of sweet acidophilus milk to improve utilization by lactoseintolerant persons', The American journal of clinical nutrition, 45(3), pp. 570-574.

Mercenier, A., Pavan, S. and Pot, B. (2003) 'Probiotics as biotherapeutic agents: present knowledge and future prospects', Current pharmaceutical design, 9(2), pp. 175-191. 
Meurman, J. H. (2009) 'Probiotics and oral health', in Food Constituents and Oral Health, pp. 421-432.

Meurman, J. H. and Stamatova, I. (2007) 'Probiotics: contributions to oral health', Oral diseases, 13(5), pp. 443-451.

Montalto, M. et al. (2004) 'Probiotic treatment increases salivary counts of lactobacilli: a double-blind, randomized, controlled study', Digestion, 69(1), pp. 53-56.

Mundula, T. et al. (2019) 'Effect of Probiotics on Oral Candidiasis: A Systematic Review and Meta-Analysis', Nutrients, 11(10). doi: 10.3390/nu11102449.

Nadelman, P. et al. (2018) 'Are dairy products containing probiotics beneficial for oral health? A systematic review and meta-analysis', Clinical oral investigations, 22(8), pp. 2763-2785.

Nandakumar, M. and Nasim, I. (2018) 'Comparative evaluation of grape seed and cranberry extracts in preventing enamel erosion: An optical emission spectrometric analysis', Journal of conservative dentistry: JCD, 21(5), pp. 516-520.

Nikawa, H. et al. (2004) 'Lactobacillus reuteri in bovine milk fermented decreases the oral carriage of mutans streptococci', International journal of food microbiology, 95(2), pp. 219-223.

Penders, J. et al. (2006) 'Factors influencing the composition of the intestinal microbiota in early infancy', Pediatrics, 118(2), pp. 511-521.

Perdigon, G. et al. (1995) 'Immune system stimulation by probiotics', Journal of dairy science, 78(7), pp. 1597-1606.

Perez, P. F. et al. (2007) 'Bacterial Imprinting of the Neonatal Immune System: Lessons From Maternal Cells?', Pediatrics, 119(3), pp. e724-e732.

Petersson, L. G. et al. (2011) 'Reversal of primary root caries lesions after daily intake of milk supplemented with fluoride and probiotic lactobacilli in older adults', Acta odontologica Scandinavica, 69(6), pp. 321-327. Poorni, S., Srinivasan, M. R. and Nivedhitha, M. S. (2019) 'Probiotic strains in caries prevention: A systematic review', Journal of conservative dentistry: JCD, 22(2), pp. 123-128.

Rajakeerthi, R. and Ms, N. (2019) 'Natural Product as the Storage medium for an avulsed tooth - A Systematic Review', Cumhuriyet Dental Journal, 22(2), pp. 249256.

Rajendran, R. et al. (2019) 'Comparative Evaluation of Remineralizing Potential of a Paste Containing Bioactive Glass and a Topical Cream Containing Casein Phosphopeptide-Amorphous Calcium Phosphate: An in Vitro Study', Pesquisa brasileira em odontopediatria e clinica integrada, 19(1), pp. 1-10.

Ramarao, S. and Sathyanarayanan, U. (2019) 'CRA
Grid - A preliminary development and calibration of a paper-based objectivization of caries risk assessment in undergraduate dental education', Journal of conservative dentistry: JCD, 22(2), pp. 185-190.

Saavedra, J. M. et al. (2004) 'Long-term consumption of infant formulas containing live probiotic bacteria: tolerance and safety', The American journal of clinical nutrition, 79(2), pp. 261-267.

Schlagenhauf, U. et al. (2016) 'Regular consumption of Lactobacillus reuteri-containing lozenges reduces pregnancy gingivitis: an RCT', Journal of clinical periodontology, 43(11), pp. 948-954.

Schwendicke, F. et al. (2014) 'Cariogenic Effects of Probiotic Lactobacillus rhamnosus GG in a Dental Biofilm Model', Caries research, 48(3), pp. 186-192.

Seminario-Amez, M. et al. (2017) 'Probiotics and oral health: A systematic review', Medicina Oral Patología Oral y Cirugia Bucal, pp. 0-0. doi: 10.4317/ medoral.21494.

Shimauchi, H. et al. (2008) 'Improvement of periodontal condition by probiotics with Lactobacillus salivarius WB21: a randomized, double-blind, placebo-controlled study', Journal of clinical periodontology, 35(10), pp. 897-905.

Siddique, R. et al. (2019) 'Qualitative and quantitative analysis of precipitate formation following interaction of chlorhexidine with sodium hypochlorite, neem, and tulsi', Journal of conservative dentistry: JCD, 22(1), pp. 40-47.

Siddique, R. and Nivedhitha, M. S. (2019) 'Effectiveness of rotary and reciprocating systems on microbial reduction: A systematic review', Journal of conservative dentistry: JCD, 22(2), pp. 114-122.

Siddique, R., Nivedhitha, M. S. and Jacob, B. (2019) 'Quantitative analysis for detection of toxic elements in various irrigants, their combination (precipitate), and para-chloroaniline: An inductively coupled plasma mass spectrometry study', Journal of conservative dentistry: JCD, 22(4), pp. 344-350.

Silva, M. et al. (1987) 'Antimicrobial substance from a human Lactobacillus strain', Antimicrobial agents and chemotherapy, 31(8), pp. 1231-1233.

Simark-Mattsson, C. et al. (2007) 'Lactobacillusmediated interference of mutans streptococci in cariesfree vs. caries-active subjects', European journal of oral sciences, 115(4), pp. 308-314.

Snydman, D. R. (2008) 'The safety of probiotics', Clinical infectious diseases: an official publication of the Infectious Diseases Society of America, 46 Suppl 2, pp. S104-11; discussion S144-51.

Srionnual, S. et al. (2007) 'Weissellicin 110, a Newly Discovered Bacteriocin from Weissella cibaria 110, Isolated from Plaa-Som, a Fermented Fish Product from 
Thailand', Applied and environmental microbiology, 73(7), pp. 2247-2250.

Stamatova, I. et al. (2009) 'In vitroevaluation of yoghurt starter lactobacilli andLactobacillus rhamnosusGG adhesion to saliva-coated surfaces', Oral microbiology and immunology, 24(3), pp. 218-223.

Stecksén-Blicks, C., Sjöström, I. and Twetman, S. (2009) 'Effect of long-term consumption of milk supplemented with probiotic lactobacilli and fluoride on dental caries and general health in preschool children: a cluster-randomized study', Caries research, 43(5), pp. 374-381.

Tannock, G. W. (2003) 'Probiotics: time for a dose of realism', Current issues in intestinal microbiology, 4(2), pp. 33-42.

Teja, K. V., Ramesh, S. and Priya, V. (2018) 'Regulation of matrix metalloproteinase-3 gene expression in inflammation: A molecular study', Journal of conservative dentistry: JCD, 21(6), pp. 592-596.

Teughels, W. et al. (2008) 'Probiotics and oral healthcare', Periodontology 2000, 48, pp. 111-147.

Toi, C. S., Mogodiri, R. and Cleaton-Jones, P. E. (2000) 'Mutans streptococci and lactobacilli on healthy and carious teeth in the same mouth of children with and without dental caries', Microbial ecology in health and disease, 12(1). doi: 10.3402/mehd.v12i1.8042.

Ujaoney, S. et al. (2014) 'In vitro effect of over-thecounter probiotics on the ability of Candida albicans to form biofilm on denture strips', Journal of dental hygiene: JDH / American Dental Hygienists' Association, 88(3), pp. 183-189.

Vancíková, Z. et al. (2003) 'The early postnatal development of salivary antibody and immunoglobulin response in children orally colonized with a nonpathogenic, probiotic strain of E. coli', Folia microbiologica, 48(2), pp. 281-287.

Wei, H. et al. (2002) 'Stability and activity of specific antibodies against Streptococcus mutans and Streptococcus sobrinus in bovine milk fermented with Lactobacillus rhamnosus strain GG or treated at ultrahigh temperature', Oral microbiology and immunology, 17(1), pp. 9-15.

Yoshioka, H., Iseki, K. and Fujita, K. (1983) ‘Development and differences of intestinal flora in the neonatal period in breast-fed and bottle-fed infants', Pediatrics, 72(3), pp. 317-321. 